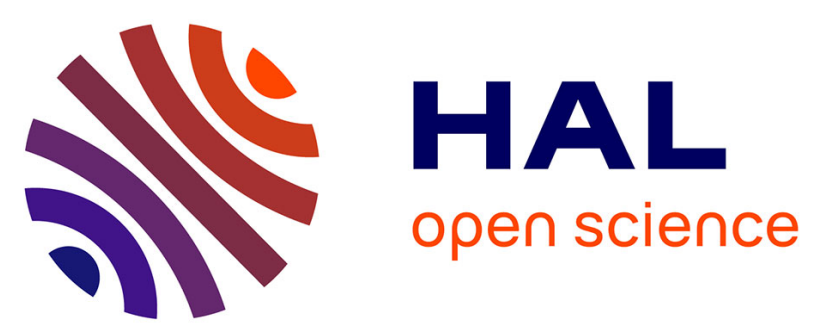

\title{
Reducing the Gap between the Activation Energy Measured in the Liquid and the Glassy States by Adding a Plasticizer to Polylactide
}

Steven Araujo, Nicolas Delpouve, Alexandre Dhotel, Sandra Domenek, Alain

Guinault, Laurent Delbreilh, Eric Dargent

\section{To cite this version:}

Steven Araujo, Nicolas Delpouve, Alexandre Dhotel, Sandra Domenek, Alain Guinault, et al.. Reducing the Gap between the Activation Energy Measured in the Liquid and the Glassy States by Adding a Plasticizer to Polylactide. ACS Omega, 2018, 3 (12), pp.17092-17099. 10.1021/acsomega.8b02474 . hal-02061741

\section{HAL Id: hal-02061741 \\ https://hal.science/hal-02061741}

Submitted on 2 Apr 2019

HAL is a multi-disciplinary open access archive for the deposit and dissemination of scientific research documents, whether they are published or not. The documents may come from teaching and research institutions in France or abroad, or from public or private research centers.
L'archive ouverte pluridisciplinaire HAL, est destinée au dépôt et à la diffusion de documents scientifiques de niveau recherche, publiés ou non, émanant des établissements d'enseignement et de recherche français ou étrangers, des laboratoires publics ou privés. 


\title{
Reducing the Gap between the Activation Energy Measured in the Liquid and the Glassy States by Adding a Plasticizer to Polylactide
}

\author{
Steven Araujo, ${ }^{\dagger}$ Nicolas Delpouve, ${ }^{*}{ }^{\dagger} \odot$ Alexandre Dhotel, ${ }^{\dagger}$ Sandra Domenek, ${ }^{\ddagger}$ Alain Guinault, ${ }^{\S}$
} Laurent Delbreilh, ${ }^{\dagger}$ and Eric Dargent ${ }^{\dagger}$

\author{
${ }^{\dagger}$ Normandie Univ, UNIROUEN Normandie, INSA Rouen, CNRS, Groupe de Physique des Matériaux, 76000 Rouen, France \\ ${ }^{\ddagger}$ UMR Ingénierie Procédés Aliments, AgroParisTech, INRA, Université; Paris-Saclay, 1 avenue des Olympiades, F-91300 Massy, \\ France
}

${ }^{\S}$ PIMM, CNAM, CNRS UMR 8006, Arts et Métiers-ParisTech, 151 bd de l’Hôpital, 75013 Paris, France

\author{
Supporting Information
}

ABSTRACT: The kinetic fragility of a glass-forming liquid is an important parameter to describe its molecular mobility. In most polymers, the kinetic fragility index obtained from the glassy state by thermally stimulated depolarization current is lower than the one determined in the liquid-like state by dielectric relaxation spectroscopy, as shown in this work for neat polylactide (PLA). When PLA is plasticized to different extents, the fragility calculated in the liquid-like state progressively decreases, until approaching the value of fragility calculated from the glass, which on the other hand remains constant with plasticization. Using the cooperative rearranging region (CRR) concept, it is shown that the decrease of the

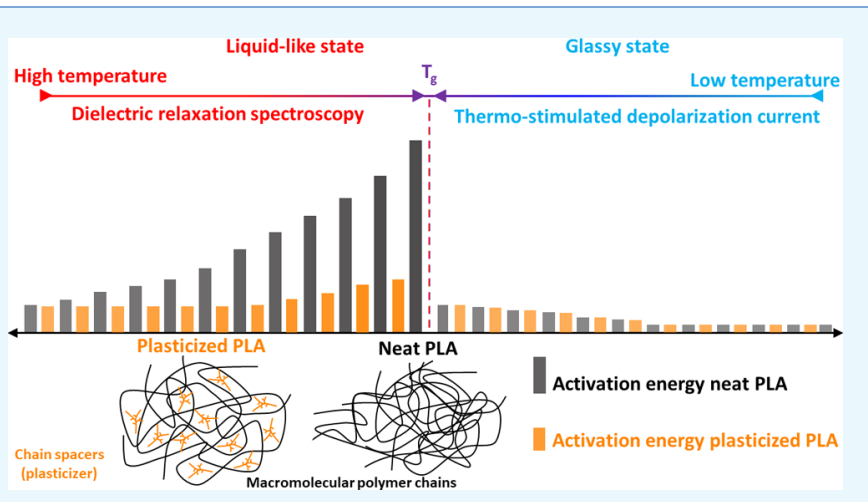
fragility in the liquid-like state is concomitant with a decrease of the cooperativity length. By splitting the fragility calculated in the liquid, in two contributions: volume and energetic, respectively, dependent and independent on cooperativity, we observed that the slope of the fragility plot in the glass is equivalent to the energetic contribution of the fragility in the liquid. It is then deduced that the difference between the slopes of the relaxation time dependence calculated in both glass and liquid is an indicator of the cooperative character of the segmental relaxation when transiting from liquid to glass. As the main structural consequence of plasticization lies in the decrease of interchain weak bonds, it is assumed that these bonds drive the size of the CRR. In contrast, the dynamics in the glass are independent on plasticization structural effects.

\section{INTRODUCTION}

The fragility index $m$ (eq 1 ) introduced by Angell ${ }^{1}$ is a physical parameter of glass-forming liquids, including polymers, that characterizes the degree of deviation from the Arrhenius-type temperature dependence of relaxation time, when approaching the glass transition during cooling. High deviations involve high values of $m$. The polymer in that case is considered "fragile". In contrast, if the temperature dependence of the relaxation time $\tau(T)$ fits the Arrhenius-type behavior, the polymer is "strong". 1

$$
m=\left.\frac{\mathrm{dlog}_{10}(\tau)}{\mathrm{d}\left(T / T_{\mathrm{g}}\right)}\right|_{T=T_{\mathrm{g}}}
$$

The fragility index can be obtained from the recording of the temperature dependence of the relaxation time, from dielectric relaxation spectroscopy (DRS) as an example. The method of thermally stimulated depolarization current (TSDC) is also successfully used to characterize the large-scale segmental motions responsible for the glass transition. The fragility index may be calculated as well from both techniques ${ }^{2}$ with eq 1 . In TSDC, the sample is placed between parallel electrodes, acting as a capacitor, and is submitted to a dc electric field at polarization temperature $T_{\mathrm{p}}$, which situates generally slightly above the glass-transition temperature $T_{\mathrm{g}}$. As a result of the electric field, dipoles reorient within the polymer. Then, the polarized sample is cooled down, keeping the electric field applied, to a temperature at which the characteristic relaxation time is significantly longer. Therefore, when removing the electric field, the polarization is maintained. The polarized sample is then reheated, and the electric current produced by the depolarization process is recorded as a function of time. A peak is obtained when approaching the glass transition. Alegria et $\mathrm{al}^{3}$ showed that the TSDC experiments regarding the segmental relaxation of polymers can be consistently analyzed in the same framework often used for conventional DRS

Received: September 21, 2018

Accepted: November 29, 2018

Published: December 12, 2018 
experiments, that is, in terms of the Kohlrausch-WilliamsWatts (KWW) equation. ${ }^{4,5}$ Thus, TSDC and DRS are complementary because the latter provides the temperature dependence of the relaxation time in the liquid-like state when the former extends the drawing of the relaxation map to the glassy state. ${ }^{6}$ Consequently, the fragility index calculated from both techniques may differ because the pathway to the glass transition is different. In this paper, they are noted as $m_{\text {glass }}$ and $m_{\text {liquid }}$ when respectively referring to TSDC and DRS data.

Some systems, such as indomethacin, ${ }^{7}$ diglycidyl ether of bisphenol-A, ${ }^{8}$ pentachloronitrobenzene, ${ }^{9}$ or glycerol, ${ }^{10}$ exhibit close values between $m_{\text {glass }}$ and $m_{\text {liquid }}$. In other cases, higher values of $m_{\text {liquid }}$ are reported. ${ }^{11-13}$ Several authors ${ }^{14-16}$ observed that the discrepancy between fragility values obtained from various experimental techniques is more pronounced for high-fragility glass-forming liquids. According to Hutchinson, ${ }^{15}$ strong glass-forming supercooled liquids are those for which there is very little change in the slope of the fragility plot on passing from the equilibrium melt to the nonequilibrium glass, whereas fragile glass-forming liquids exhibit a large change in the slope of the fragility plot as the glass-transition region is traversed on cooling. Arnoult et al. ${ }^{17}$ investigated the relaxation dynamics in polylactide (PLA) from both techniques and reported that $m_{\text {glass }}=118$ and $m_{\text {liquid }}=189$. A correlation between $m_{\text {liquid }}$ and the molecular structure has been proposed by Kunal et al. ${ }^{18}$ and Dudowicz et al. ${ }^{19}$ Polymers with very stiff backbones exhibit high fragility index. As an example, the values of $m_{\text {liquid }}$ equal to 132,156 , and 214 for polycarbonate (PC), poly(ethylene terephthalate), and poly(etherimide), respectively, were reported. ${ }^{20}$ On the other hand, polymers with very flexible backbones, such as polyisobutylene and polyethylene, for which $m_{\text {liquid }}$ is close to $50,{ }^{20}$ are among the strongest. However, no clear correlation has yet been established between the polymer structure and the difference between $m_{\text {glass }}$ and $m_{\text {liquid }}$.

In this study, the impact of PLA plasticization on its relaxation map has been investigated. To do so, DRS, TSDC, and modulated temperature differential scanning experiments (MT-DSCs) have been combined. The addition of a plasticizer during the formulation of PLA is a common procedure that lowers its inherent brittleness and decreases its glass-transition temperature. The structural consequences, when increasing the plasticizer content, can be anticipated with a simple description, by considering a minor impact on the macromolecular chain while progressively lowering the interchain bonding. ${ }^{21-24}$ Our objective is to investigate how this selective interchain bond breaking affects the glass-transition dynamics.

\section{RESULTS AND DISCUSSION}

Impact of Plasticization on Glass-Transition Signatures. In Figure 1 are given the glass-transition signatures obtained for neat and plasticized PLA from the out-of-phase component $C^{\prime \prime}$ of the complex heat capacity $C^{*}$ obtained by MT-DSC as a function of temperature (Figure 1a), the depolarization current versus temperature by TSDC (Figure $1 \mathrm{~b})$, and the imaginary part of the dielectric permittivity in a frequency domain by DRS (Figure 1c). As observed from previous MT-DSC reports, ${ }^{25-27}$ the dynamic glass-transition temperature determined from the maximum of the $C^{\prime \prime}$ peak, $T_{\alpha \text { MT-DSC, }}$ is shifted toward lower temperatures when plasticizer is added to PLA (Figure 1a). Similarly, $T_{\alpha \text { TSDC, }}$ the maximum temperature of the depolarization peak, shifts toward a lower temperature when the plasticizer content
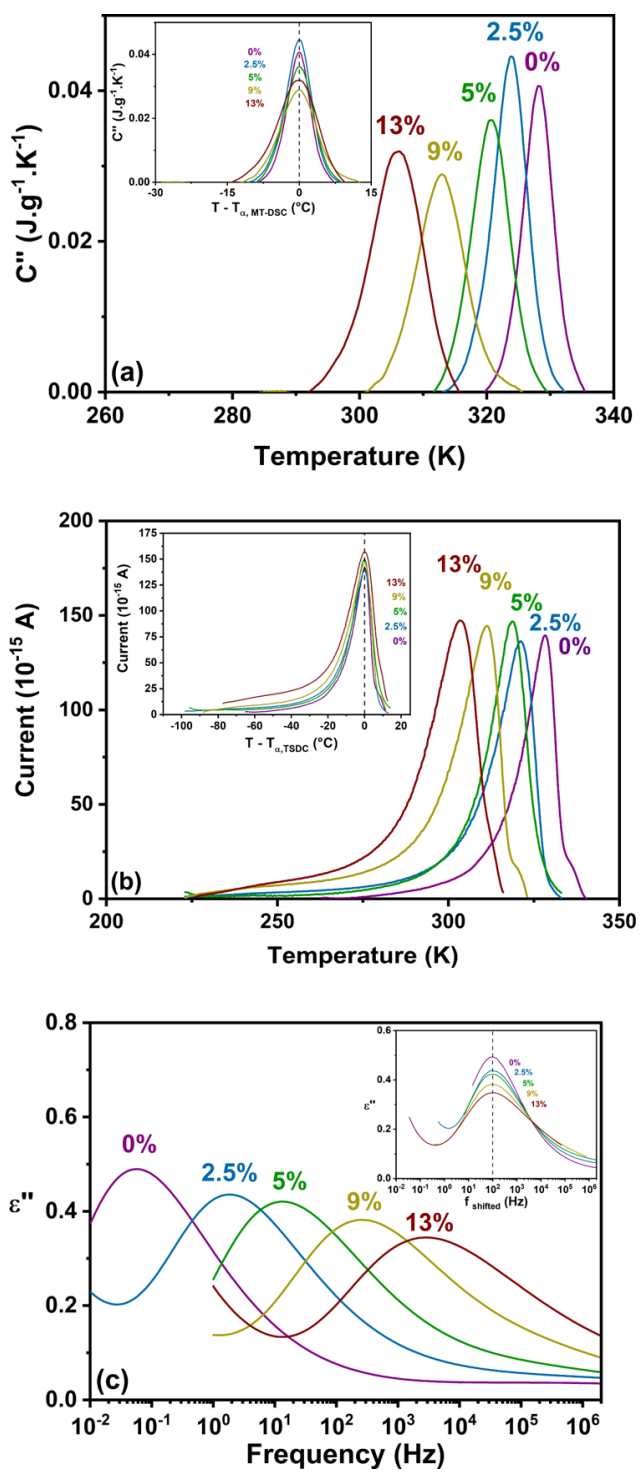

Figure 1. Glass-transition signature obtained from MT-DSC, TSDC, and DRS for all samples: neat (purple), 2.5\% ATBC (blue), 5\% (green), 9\% (yellow), and 13\% (brown). In the insets, the results are rescaled to the maximum response for each sample: (a) out-of-phase $C^{\prime \prime}$ signal of the complex heat capacity $C^{*}$ as a function of temperature obtained by MT-DSC, (b) recorded depolarization current as a function of temperature from TSDC, and (c) imaginary part $\varepsilon^{\prime \prime}$ of the complex permittivity $\varepsilon^{*}$ as a function of frequency obtained by DRS measurements at $332 \mathrm{~K}$.

increases (Figure 1b). The segmental relaxation was also investigated above the glass-transition temperature through DRS. The results are displayed in Figure 1c at $332 \mathrm{~K}$ for each sample. The segmental relaxation (at a fixed temperature) shifts toward higher frequencies when PLA is plasticized. This is characteristic of an increase of the molecular mobility with plasticization. Besides, the $\alpha$-relaxation temperature $T_{\alpha \text { DRS, }}$ calculated for each sample (at the relaxation time $\tau=100 \mathrm{~s}$ ), as well as other characteristic temperatures was reported in Table 1. It decreases with the plasticizer content in consistent with MT-DSC and TSDC results. Overall, a good agreement is obtained between these three techniques. In addition, it can be seen in each inset of Figure 1 that the width of the glasstransition signature broadens as the plasticizer content increases from 0 to $13 \% \mathrm{w} / \mathrm{w}$. Such broadening of the glass 
Table 1. Segmental Relaxation Parameters for Neat and Plasticized PLA

$\begin{array}{llllll}x \% \text { ATBC } & 0 & 2.5 & 5 & 9 & 13 \\ T_{\alpha \text { TSDC }}(\mathrm{K})^{a} & 328.0 & 321.0 & 319.0 & 311.0 & 303.5 \\ T_{\alpha \text { MT-DSC }}(\mathrm{K})^{a} & 328.0 & 324.0 & 320.5 & 313.0 & 306.0 \\ T_{\alpha \text { DRS }}(\mathrm{K})^{a, e} & 327.5 & 322.0 & 318.5 & 310.5 & 304.0 \\ T_{\text {g,intersection }}(\mathrm{K})^{a} & 327.5 & 323.0 & 320.0 & 314.0^{f} & 308.5^{f} \\ \log _{10}\left[(\tau)_{\text {intersection }}(\mathrm{s})\right] & 1.81 & 1.55 & 1.53 & 0.96 & 0.72 \\ E_{\mathrm{a}, \mathrm{DRS}}\left(\mathrm{kJ} \mathrm{mol}^{-1}\right)^{b} & 932 & 781 & 731 & 566 & 476 \\ E_{\mathrm{a}, \mathrm{TSDC}}\left(\mathrm{kJ} \mathrm{mol}^{-1}\right)^{b} & 364 & 452 & 390 & 438 & 448 \\ \left.\Delta E_{\mathrm{a}}(\mathrm{kJ} \mathrm{mol})^{-1}\right) & 568 & 328 & 341 & 128 & 28 \\ \xi_{T_{a \mathrm{MT}-\mathrm{DSC}}}\left(\mathrm{nm}^{c}\right. & 3.3 & 3.0 & 2.8 & 2.4 & 2.0 \\ m_{\text {liquid }}{ }^{c} & 152 & 133 & 125 & 102 & 87 \\ m_{\text {glass }}{ }^{c} & 57 & 69 & 58 & 68 & 70 \\ m_{\mathrm{V}}{ }^{c} & 67 & 69 & 73 & 69 & 68 \\ \beta_{\mathrm{KWW}} & 0.70 & 0.65 & 0.61 & 0.47 & 0.39 \\ \Delta C_{p}\left(\mathrm{~J} \mathrm{~g}^{-1} \mathrm{~K}^{-1}\right)^{d} & 0.50 & 0.54 & 0.51 & 0.55 & 0.50\end{array}$

${ }^{a}$ Values are given with an uncertainty of $0.5 \mathrm{~K} .{ }^{b}$ Values are given with an uncertainty of $10 \%$. ${ }^{c}$ Values are given with an uncertainty of $10 \%$. ${ }^{d}$ Values are given with an uncertainty of $0.04 \mathrm{~J} \mathrm{~g}^{-1} \mathrm{~K}^{-1}$. ${ }^{e} T_{\alpha \text { DRS }}$ is calculated from the extrapolation of the $\mathrm{VFT}^{28-30}$ law fitting at $\tau=$ $100 \mathrm{~s}$ the experimental data of relaxation time as a function of temperature (see Figure 2). ${ }^{f}$ Obtained by extrapolation of TSDC experimental data with a polynomial law $\left(y=A_{0}+A_{1} \times x+A_{2} \times x^{2}+\right.$ $\left.A_{3} \times x^{3}+A_{4} \times x^{4}+A_{5} \times x^{5}\right)$.

transition when PLA is plasticized by acetyl tributyl citrate (ATBC) has also been reported in previous studies. ${ }^{25-27}$

Relaxation Map of Plasticized PLA. The relaxation map aims at capturing the temperature dependence of the segmental relaxation dynamics in a temperature domain from either side of calorimetric glass transition. The segmental relaxation in the liquid-like state obtained through DRS exhibits a non-Arrhenius character, which can be described by eq 2 of Vogel-Fulcher-Tammann (VFT). ${ }^{28-30}$

$$
\tau=\tau_{0} \exp \left(\frac{D T_{0}}{T-T_{0}}\right)
$$

where $\tau$ is the relaxation time corresponding to the maximum of the relaxation time distribution, $\tau_{0}$ is a pre-exponent factor, $D$ is a steepness parameter, and $T_{0}$ is the Vogel temperature. From TSDC, as proposed by Alegria et al., ${ }^{31}$ the segmental relaxation can be consistently analyzed in terms of the KWW equation. ${ }^{4,5}$ The relaxation times $(\tau)$ associated with the segmental relaxation were calculated according to eq $3^{3}$

$$
\tau=\beta \frac{Q}{I}\left[\ln \frac{Q_{0}}{Q}\right]^{[1-1 / \beta]}
$$

where $Q(t)=\int_{t}^{\infty} I \mathrm{~d} t, Q_{0}$ is the value of the initial stored charge, $I$ is the intensity, and $\beta$ is a parameter depicting the non-Debye character of the segmental relaxation. The $\beta$ or

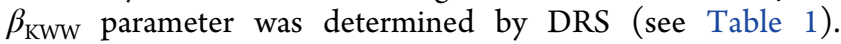
Finally, the dynamic glass-transition temperature obtained from MT-DSC was added for each sample. MT-DSC measurements were performed with an oscillation period of $80 \mathrm{~s}$ corresponding to a solicitation frequency about 0.0125 $\mathrm{Hz}$, which provides $T_{\alpha \text { MT-DSC }}$ at a given relaxation time $\tau$ equal to $13 \mathrm{~s}$ approximately. The results are presented in Figure 2.

The relaxation map highlights the difference in dynamics for the segmental relaxation of neat PLA in both glass and liquid states. When approaching the glass transition on cooling

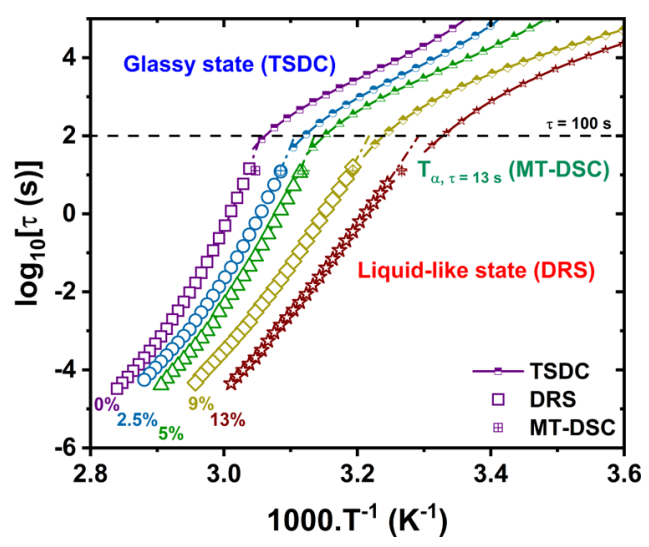

Figure 2. Relaxation map picturing the characteristic relaxation time of the segmental relaxation as a function of the inverse temperature obtained from MT-DSC, TSDC, and DRS. Empty symbols correspond to the DRS results, crossed symbols to the MT-DSC results, and half-filled symbols to the TSDC results.

(DRS), the temperature dependence of the relaxation time strongly deviates from conventional Arrhenius law (given in eq 4). Instead of a linear dependence, we observe that the relaxation time increases more rapidly when approaching the glass transition. Its dependence with temperature was fitted following eq 2 .

$$
\tau=\tau_{0} \exp \left(\frac{E_{\mathrm{a}}}{R T}\right)
$$

On the other hand, TSDC relaxation times exhibit Arrhenius-like behavior far from the glass transition and a weak curvature close to the glass transition for every sample. As a consequence, $m_{\text {liquid }}$ and $m_{\text {glass }}$ calculated according to eq 1 for $T_{\mathrm{g}}=T_{\alpha}(\tau=100 \mathrm{~s})$ are different: $m_{\text {liquid }}=152$ and $m_{\text {glass }}=$ 57. The values for all systems are summarized in Table 1 .

With the addition of plasticizer to PLA, $m_{\text {liquid }}$ decreases from 152 for neat PLA to 87 for PLA/13\%. In contrast, the variation of $m_{\text {glass }}$ with plasticization is not significant: $m_{\text {glass }}$ situates between 57 and 70 for all systems. Thus, the high difference initially observed for neat PLA between the two values is progressively erased with plasticization.

Cooperativity and Nature of the Glass-Transition Dynamics. As expected, plasticization shifts the segmental relaxation to lower temperatures for a given relaxation time in both glass and liquid. As shown in Figure 3a, the decrease of the glass-transition temperature follows a linear trend with the plasticizer weight content. The broadening of the glasstransition signature with plasticization reveals a wider distribution of temperatures associated with the segmental relaxation. TSDC and DRS relaxation time results are supposed to intersect with each other at a given temperature corresponding to the glass-transition temperature. The intersection characteristics, in terms of temperature $T_{\text {g,intersection }}$ and relaxation time $\tau_{\text {intersection }}$ are summarized in Table 1 . The relaxation time $\tau=100 \mathrm{~s}$ (marked in Figure 2) is used as the reference time for determining the glass-transition temperature. However, it is observed (Figure $3 \mathrm{~b}$ ) that the intersection point progressively shifts in relaxation time with plasticization. Although it initially occurs at a relaxation time equal to $65 \mathrm{~s}$ for neat PLA, it deviates down to $5 \mathrm{~s}$ for PLA/13\%. Besides, $\log _{10}\left[(\tau)_{\text {intersection }}(\mathrm{s})\right]$ follows a linear trend with the plasticizer weight content (Figure $3 b$ ). To assess whether this result 

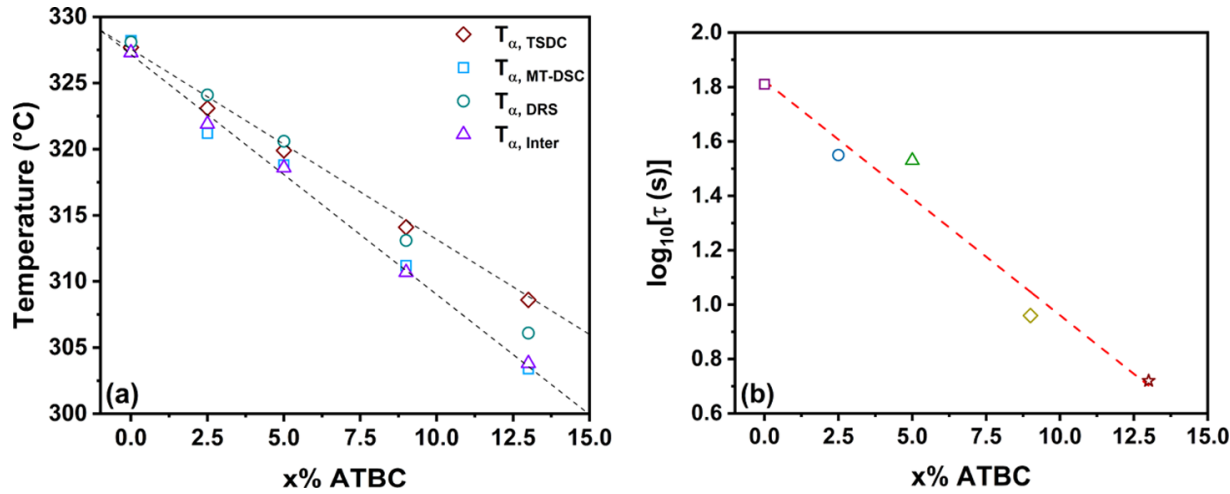

Figure 3. (a) Dynamic glass-transition temperature versus plasticizer weight content assessed from TSDC, MT-DSC, and DRS measurements. Dashed lines delimit an experimental domain for the dynamic glass-transition temperature. (b) Log (relaxation time) vs plasticizer content obtained from the intersection point between TSDC and DRS results. This variation follows a linear trend (dashed line).

corresponds to a change of dynamics related to plasticization or to an uncertain determination of $\tau_{\text {intersection }}$ the activation energy associated with the segmental relaxation has been calculated thanks to eq 5 .

$$
E_{\mathrm{a}}=\frac{\partial \ln (\tau)}{\partial\left(1 / T_{\alpha}\right)} R
$$

where $\tau$ is the characteristic time of the segmental relaxation at $T_{\alpha}$ and $R$ is the gas constant. The results are presented in Figure 4 in a normalized plot $T_{\text {g,intersection }} / T$. The values of

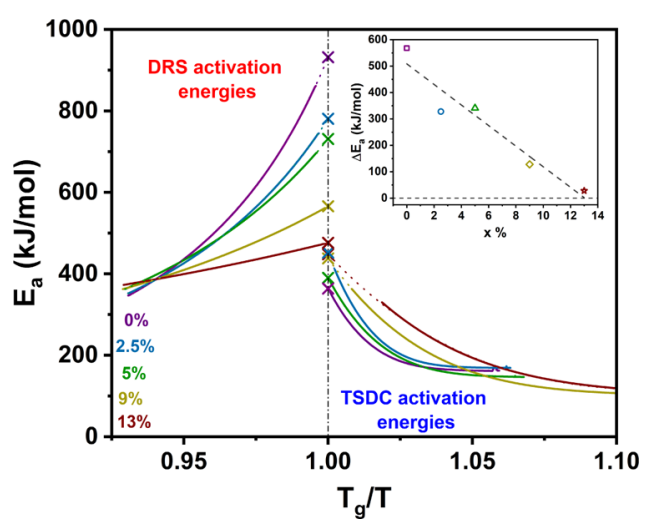

Figure 4. Activation energy as a function of $T_{\text {g,intersection }} / T$ calculated from TSDC and DRS results. The inset shows the gap of activation energy at the glass-transition temperature between both techniques as a function of the plasticizer weight content. Cross shape points correspond to the activation energy values extrapolated at $T_{\text {g,intersection }} /$ $T=1$.

activation energy obtained at $T_{\text {g,intersection }} / T=1$ from the liquid $E_{\mathrm{a}, \mathrm{DRS}}$ and the glass $E_{\mathrm{a}, \mathrm{TSDC}}$ are given in Table 1, as well as $\Delta E_{\mathrm{a}}$ the difference between these two values, also presented in the inset of Figure 4 as a function of the plasticizer weight content.

In the supercooled liquid, for $T_{\text {g,intersection }} / T \leq 0.95$, the activation energy is roughly the same (about $400 \mathrm{~kJ} \mathrm{~mol}^{-1}$ ) independently on the plasticizer content. When the temperature decreases, the activation energy increases exponentially for neat PLA until reaching a maximum value of $932 \mathrm{~kJ} \mathrm{~mol}^{-1}$ for $T_{\text {g,intersection }} / T=1$. The increase of activation energy during cooling is less and less brutal when increasing the plasticizer content in PLA and is almost linear versus $T_{\text {g,intersection }} / T$ for PLA/13\%. Therefore, the value of $E_{\mathrm{a}, \mathrm{DRS}}$ decreases importantly with plasticization and reaches its minimum equal to $476 \mathrm{~kJ}$ $\mathrm{mol}^{-1}$ for PLA/13\%. The activation energy trends obtained from TSDC are quite different. For low temperatures, the activation energy versus $T_{\text {g,intersection }} / T$ seems to reach an asymptotic value. Constant values of activation energy about $100 \mathrm{~kJ} \mathrm{~mol}^{-1}$ are observed for neat PLA, PLA/2.5\%, and PLA/ $5 \%$ for the lowest temperatures. When approaching the glass transition, the activation energy increases until reaching the value $E_{\mathrm{a}, \mathrm{TSDC}}$ for $T_{\mathrm{g} \text {,intersection }} / T=1$. This change in the molecular dynamics does not compare, however, with what is observed in the liquid state. The highest value obtained for $E_{\mathrm{a}, \mathrm{TSDC}}$ is close to the lowest value obtained for $E_{\mathrm{a}, \mathrm{DRS}}$. Besides, the variations of $E_{\mathrm{a}, \mathrm{TSDC}}$ with the plasticizer content do not follow a clear trend and might not be significant. An average value about $400 \mathrm{~kJ} \mathrm{~mol}^{-1}$ might be considered, which is of the same order as the activation energy in the supercooled liquid, for $T_{\text {g,intersection }} / T \leq 0.95$. As a result, $\Delta E_{\mathrm{a}}$ decreases with the ATBC weight percentage following a linear tendency.

It is worth analyzing these results in the frame of the cooperative rearranging region (CRR) concept introduced by Adam and Gibbs. ${ }^{32}$ Many studies associate the so-called viscous slowing down of supercooled liquids with the increase in the energy barrier that the structural units must overcome for the relaxation process to occur. ${ }^{33-36}$ One can assume that $E_{\mathrm{a}, \mathrm{DRS}}$ decreases with plasticization because of the less cooperative character of the segmental relaxation dynamics. Adam and $\mathrm{Gibbs}^{32}$ define the CRR as the smallest subsystems in which the main relaxation process occurs independently of the dynamics of the neighboring subsystems, so that each region is characterized by its own thermodynamic variables and relaxation dynamics. The possibility to calculate, $\xi_{T_{\alpha}}{ }^{3}$, the volume of a CRR from the relaxation temperatures or relaxation time distribution is suggested by Donth, ${ }^{37}$ using the thermodynamic fluctuation approach (eq 6).

$$
\xi_{T_{\alpha}}{ }^{3}=\frac{\left(\frac{1}{C_{p \text { glass } T_{\alpha}}}-\frac{1}{C_{p \text { liquid } T_{\alpha}}}\right) k_{\mathrm{B}} T_{\alpha}{ }^{2}}{\alpha \delta T^{2}}
$$

where $C_{p}$ is the specific heat capacity at constant pressure, $k_{\mathrm{B}}$ is the Boltzmann's constant, $T_{\alpha}$ is the dynamic glass-transition temperature, $\rho$ is the density, and $\delta T$ is the mean square temperature fluctuation associated with the glass transition. From the in-phase and out-of-phase components of the complex heat capacity measured from MT-DSC, the cooperativity length $\xi_{T_{\alpha \mathrm{MT} \text {-DSC }}}$ has been calculated. Results are shown in Table 1. By plasticizing PLA, $\xi_{T_{\alpha \mathrm{MT} \text {-DSC }}}$ decreases from 

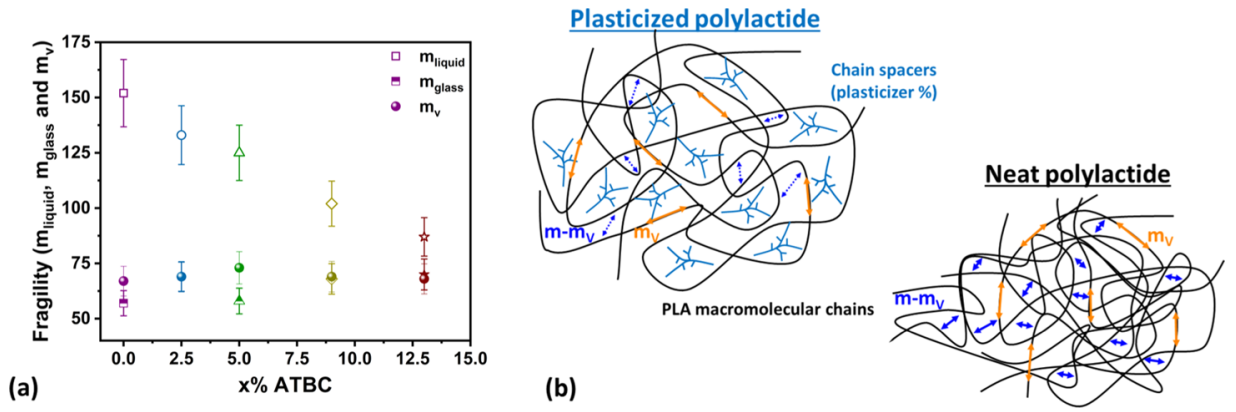

Figure 5. (a) $m_{\text {glass }}$ and $m_{\text {liquid }}$ calculated from TSDC and DRS measurements, respectively, using eq 1 , and isochoric fragility $m_{\mathrm{V}}$ obtained from eq 7. (b) Structural representation of the two components governing the liquid fragility in neat and plasticized PLA: $\left(m-m_{\mathrm{V}}\right)$ depends on the intermolecular interactions, whereas $m_{\mathrm{V}}$ characterizes the stiffness of the backbone. $\left(m-m_{\mathrm{V}}\right)$ is represented by dashed arrows in plasticized PLA and by straight arrows in neat PLA to highlight the respective importance of interchain interactions in both materials.

3.3 to $2.0 \mathrm{~nm}$ in consistent with previous observations. ${ }^{25-27}$ Therefore, the difference in the liquid-like state between the dynamics of neat and plasticized PLA can be related to the more or less cooperative character of the segmental relaxation. On the other hand, no correlation is found between the cooperativity length and the segmental relaxation dynamics in the glass that occur similarly independently on the plasticizer content.

Structural Interpretation of Fragility Dependence on the Dynamic Nature. Many hypotheses were proposed in the literature to explain the difference between $m_{\text {liquid }}$ and $m_{\text {glass }}$ in fragile glass-forming liquids. It was suggested, for example, that these differences could be attributed to the nonexponentiality of the segmental relaxation, ${ }^{13,38}$ so the ratio between fragility values and $\beta_{\mathrm{KWW}}$ would be equivalent. As shown in Table 1 , for the most plasticized system, $\beta_{\mathrm{KWw}}=0.39$ while $m_{\text {liquid }} / m_{\text {glass }}$ is close to 1 . Thus, our experimental data do not fit this assumption. On the other hand, it has been discussed above that a good correlation is found between $\Delta E_{\mathrm{a}}$ and $\xi_{T_{\alpha \mathrm{MT} \text {-DSC}}}$, reflecting the degree of cooperativity associated with the segmental relaxation in the liquid state. Sokolov et al. ${ }^{39}$ reported from Raman spectroscopy that strong glass formers exhibit a high ratio between vibrational and relaxation contributions in comparison to fragile glass formers. This would imply that the difference in cooperativity between neat and plasticized PLA, which reflects in $m_{\text {liquid }}$, has a structural causality.

Hong et al. ${ }^{40}$ separated $m_{\text {liquid }}$ into two contributions: the isochoric fragility $m_{\mathrm{V}}$ associated with the temperature dependence of the structural relaxation time at constant volume and the balance $\left(m-m_{\mathrm{V}}\right)$ that corresponds to the volume contribution. According to this assumption, $m_{\text {liquid }}$ can be expressed as

$$
m_{\text {liquid }}=m_{\mathrm{V}}+\frac{\Delta V^{\#}}{\ln (10) k_{\mathrm{B}}} \frac{\alpha_{\mathrm{T}}}{\kappa}
$$

where $\kappa$ is the compressibility and $\alpha_{\mathrm{T}}$ is the coefficient of thermal expansion of the supercooled liquid at $T_{\mathrm{g}}$. The ratio $\alpha_{\mathrm{T}} / \kappa$ goes from 0.5 to $3.0 \mathrm{MPa} / \mathrm{K}$ for a wide range of glass formers, and $\Delta V^{\#}$ is equal to approximately $5 \%$ of the cooperativity volume. Thus, only the parameter $\left(m-m_{\mathrm{V}}\right)$ is assumed to be directly correlated with the cooperativity at the glass transition. By assuming that the difference between $m_{\text {liquid }}$ and $m_{\text {glass }}$ could be correlated with the cooperativity length, $m_{\mathrm{V}}$ should be close to $m_{\text {glass. }}$. The results presented in Figure 5a for a ratio $\alpha_{\mathrm{T}} / \kappa=1.5 \mathrm{MPa} / \mathrm{K}$ (an average value with respect to those reported by Hong et al. ${ }^{40}$ for different polymers) show indeed a good consistence between the values of $m_{\mathrm{V}}$ and $m_{\text {glass. }}$.

Recently, ${ }^{41}$ we proposed a structural interpretation of the two components governing the liquid fragility in polymers. In this representation, $\left(m-m_{\mathrm{V}}\right)$ depends on the interchain interactions, whereas $m_{\mathrm{V}}$ characterizes the stiffness of the backbone. This interpretation, depicted in Figure $5 b$, is supported in this study by the progressive decrease with plasticization of $m_{\text {liquid }}$ while keeping $m_{\mathrm{V}}$ quite constant. Indeed, plasticization is expected to interrupt the noncovalent bonding between the macromolecules without damaging the covalent bonding. ${ }^{21-24}$ Besides, many authors have evidenced a correlation between the cooperativity length and the nature and content of interchain interactions. Nakanishi et al. ${ }^{42}$ proposed, for example, a simplified model of hydrogenbonding network that supports the increase in the CRR size with intermolecular bonds. Dhotel et al. $^{43}$ showed that monomers of 11-bromoundecyltrimethoxysilane organized in self-assembled monolayers exhibit cooperative relaxation because of the strong interactions between bromoalkyl end groups at the opposite side of the surface. On the other hand, the decrease of interchain bonds, such as van der Waals bonds, should decrease the cooperativity length, as reported when electron-donor and electron-acceptor side groups are associated in statistical methacrylate copolymers, ${ }^{44}$ or when $\pi$-stacking is hindered in PC. ${ }^{45}$

The additional role of structure to the segmental relaxation was already suggested by authors interpreting the change of the slope of $\tau(T)$ at the glass transition on the basis of the ToolNarayanaswamy-Moynihan model (eq 8), ${ }^{46-48}$ in such a way that $m_{\text {glass }} / m_{\text {liquid }}=x$, the nonlinearity parameter.

$$
\tau=\tau_{0} \exp \left(\frac{x \Delta h^{*}}{R T}\right) \exp \left(\frac{(1-x) \Delta h^{*}}{R T_{\mathrm{f}}}\right)
$$

where $\tau_{0}$ is the relaxation time at infinite temperature, $\Delta h^{*}$ is the apparent activation energy, and $T_{\mathrm{f}}$ is the fictive temperature. The first exponential characterizes the temperature dependence, whereas the second characterizes the structure dependence. Although contradictory results have been reported ${ }^{13}$ regarding the equality between the nonlinearity parameter and the ratio between fragility indexes, this interpretation exhibits common features with our results. Godard et al. ${ }^{49}$ reported, for example, that an increase of the distance of separation of the main chains, similar to the plasticization effect, results in a decrease of the structural exponential term when the temperature dependence term 
remains constant. One may draw a parallel with the decrease of $\left(m-m_{\mathrm{V}}\right)$ while keeping $m_{\mathrm{V}}$ constant during PLA plasticization. In the present study, this structural contribution is specifically attributed to the additional participation of neighboring structural units to the segmental relaxation thanks to interchain bonds, that is, the cooperativity increase.

\section{CONCLUDING REMARKS}

The evolution of activation energy associated with the segmental relaxation dynamics differs depending on the pathway to the glass transition. From the glass, the dynamics are initially Arrhenius-like at low temperature; then, the activation energy progressively increases during heating. In the liquid-like state, the possibility that the segmental relaxation mobilizes a higher number of structural units exists. The consequence of such an increase of the cooperativity during cooling is that the activation energy also increases toward the glass transition in higher proportions compared to what is observed in the glassy state. This leads to calculate significantly higher fragility index in the liquid from DRS than in the glass from TSDC. The specific structural modification generated by plasticization on PLA, that is, the selective breaking of noncovalent bonds, allows reducing the volume contribution to the liquid fragility without impacting the energetic contribution. As an illustration of the important role played by the interchain cooperativity in the viscous slowing down, this procedure erases the difference between fragility indexes calculated from the glass and the liquid. It is worth mentioning that the conclusions drawn in this paper should be accurate for any system series in which the changes in the molecular dynamics are mostly caused by any modification of the interchain interactions.

\section{EXPERIMENTAL SECTION}

Materials and Sample Preparation. Sample preparation procedure has been explained in Delpouve et al. ${ }^{27}$ PLA 4042D (about $96 \%$ of L-lactide and $4 \%$ of D-lactide) was provided by NatureWorks. ATBC (CAS number 77-90-7) was obtained from Sigma-Aldrich (France). PLA and ATBC were dried at 80 ${ }^{\circ} \mathrm{C}$ under vacuum for $12 \mathrm{~h}$ before blending in an internal mixer (Haake Rheocord 9000) at $160{ }^{\circ} \mathrm{C}$ and $60 \mathrm{rpm}$ for $15 \mathrm{~min}$. The materials were dried $\left(4 \mathrm{~h}\right.$ at $80{ }^{\circ} \mathrm{C}$ under vacuum), thermo-molded between two hot plates under 10 bars for 2 $\mathrm{min}$, and then quenched to room temperature. Plasticized PLA samples were named PLA $/ x$ ATBC films, with the weight percentage of plasticizer $x$ varying between 2.5 and $13(0 ; 2.5$; $5 ; 9 ; 13 \%)$. The average molecular weight of the PLA $\left(M_{n}=\right.$ $90500 \mathrm{~g} \cdot \mathrm{mol}^{-1}$ with dispersity $\left.=2.75\right)$ was estimated from size exclusion chromatography. The stability of ATBC into PLA was investigated and it was proved by Dobircau et al. ${ }^{25}$ that, after several thermal cycles around the glass transition, ATBC does not exude from PLA. All samples were kept amorphous during this study.

Modulated Temperature Differential Scanning Calorimetry. MT-DSC measurements were carried out by DSC Q100 (TA instruments) under nitrogen atmosphere. The samples (about $10 \mathrm{mg}$ ) were put into hermetic aluminum pans (T-Zero, TA Instruments). The calibration was carried in three steps using standards of indium and benzophenone for temperature calibration, indium for energy calibration, and sapphire for heat capacity calibration. Experiments were performed under nitrogen atmosphere $\left(70 \mathrm{~mL} \mathrm{~min}{ }^{-1}\right)$ with an oscillation amplitude $A= \pm 1.5 \mathrm{~K}$, a period $p=80 \mathrm{~s}$, and a heating rate $\beta_{\mathrm{h}}=1 \mathrm{~K} \mathrm{~min}^{-1}$. These conditions correspond to the heat cool mode, which is recommended for a clear analysis of the glass transition from which the dynamic glass-transition temperature $T_{\alpha \text { MT-DSC }}$ is determined. The modulation step number was estimated to be higher than 5 during the glass transition. The complete deconvolution procedure was done as described by Lacey et al. ${ }^{50}$ and the phase angle correction as proposed by Weyer et al. ${ }^{51}$ Before MT-DSC measurement, the samples were heated at $\beta_{\mathrm{h}}=10 \mathrm{~K} \mathrm{~min}^{-1}$ up to a temperature just above the glass-transition range and then cooled at $\left|\beta_{\mathrm{c}}\right|=$ $\beta_{\mathrm{h}}=10 \mathrm{~K} \mathrm{~min}^{-1}$ down to $0{ }^{\circ} \mathrm{C}$ in order to rejuvenate the sample.

Dielectric Relaxation Spectroscopy. Dielectric spectroscopy measurements were performed on $30 \mathrm{~mm}$ diameter and $200 \mu \mathrm{m}$ thickness samples by means of DRS with a broadband frequency response analyzer (Alpha Analyzer, Novocontrol Technologies). The temperature was controlled with a Novocontrol Quatro system. Dielectric loss measurements were acquired every $1{ }^{\circ} \mathrm{C}$ around the glass-transition range, that is, from $T_{\alpha \text { MT-DSC }}-5{ }^{\circ} \mathrm{C}$ to $T_{\alpha \text { MT-DSC }}+20{ }^{\circ} \mathrm{C}$ and over a broad frequency window from $10^{-1}$ to $10^{6} \mathrm{~Hz}$. To analyze the dielectric relaxation curves, Havriliak-Negami complex function with a conductivity term was used. ${ }^{52}$

$$
\varepsilon^{*}(\omega)=-\mathrm{i}\left(\frac{\sigma}{\omega \varepsilon_{0}}\right)^{n}+\sum_{k} \frac{\Delta \varepsilon_{k}}{\left[1+\left(\mathrm{i} \omega \tau_{k}\right)^{\alpha_{k}}\right]^{\beta_{k}}}+\varepsilon_{\infty}
$$

where $\omega$ is the angular pulsation, $\varepsilon_{0}$ is the vacuum permittivity, $\sigma$ is the conductivity, and $n$ is a fitting parameter related to the slope of the conductivity. $\Delta \varepsilon=\varepsilon_{\mathrm{s}}-\varepsilon_{\infty}$ is the relaxation strength where $\varepsilon_{\mathrm{s}}$ is the static permittivity (low frequency) and $\varepsilon_{\infty}$ is the permittivity at high frequency, $\tau$ is the relaxation time, $\alpha$ and $\beta$ are the broadening and asymmetry factors, respectively, and $k$ is the number of contributions needed to fit correctly the experimental data. The procedure to extract $\beta_{\text {KWw }}$ is given in the Supporting Information (Figure S1).

Thermo-Stimulated Depolarization Current. TSDC global experiments were performed on $30 \mathrm{~mm}$ diameter and $200 \mu \mathrm{m}$ thickness samples, with the TSDC sample cell and the 6517B electrometer/high resistance meter (Keithley) provided by Novocontrol Technologies. The temperature was controlled with a Novocontrol Quatro system. The samples were polarized in the liquid state at a temperature $T_{\mathrm{p}}=T_{\alpha \text { MT-DSC }}$ $+3{ }^{\circ} \mathrm{C}$ with a direct current of $5 \times 10^{5} \mathrm{~V} \mathrm{~m}^{-1}$ for $5 \mathrm{~min}$. The procedure for selecting the polarization temperature is given in the Supporting Information (Figure S2). It is based on obtaining the best compromise between observing the global response of the material (well-resolved peak) and also on getting rid of parasite signatures such as conductivity contributions. The samples were cooled down rapidly at $T_{\alpha \text { MT-DSC }}-40{ }^{\circ} \mathrm{C}$ while keeping the applied direct current to ensure the dipole orientation. Depolarization currents were then recorded from $T_{\alpha \text { MT-DSC }}-40{ }^{\circ} \mathrm{C}$ to $T_{\alpha \text { MT-DSC }}+15{ }^{\circ} \mathrm{C}$ with a linear temperature ramp of $10 \mathrm{~K} \mathrm{~min}^{-1}$. The TSDC experiments were performed just after cooling to minimize the physical aging effects that can strongly impact the mobility in glass and therefore the experimental results. $6,14,17,53$ 


\section{ASSOCIATED CONTENT}

\section{S Supporting Information}

The Supporting Information is available free of charge on the ACS Publications website at DOI: 10.1021/acsomega.8b02474.

Fitting procedure of the relaxation function to extract the $\beta_{\mathrm{KWW}}$ parameter from DRS experiments and TSDC results by varying the polarization temperature (PDF)

\section{AUTHOR INFORMATION}

\section{Corresponding Author}

*E-mail: nicolas.delpouve1@univ-rouen.fr. Phone: +33-(0) 232955165.

\section{ORCID}

Nicolas Delpouve: 0000-0002-6064-7151

Laurent Delbreilh: 0000-0002-9322-7153

\section{Author Contributions}

The original idea of this study is credited to Eric Dargent; Sandra Domenek and Alain Guinault were in charge of the material preparation and chromatography experiment; Nicolas Delpouve and Eric Dargent conceived MT-DSC experiments; Nicolas Delpouve performed MT-DSC experiments; Laurent Delbreilh conceived DRS and TSDC experiments, which were, respectively, performed by Steven Araujo and Alexandre Dhotel; and Steven Araujo did the data treatment. All authors without exceptions were involved in the data discussion; figures and tables were designed by Steven Araujo; the responsibility of article writing was taken by Nicolas Delpouve who benefited from precious contributions from the other authors.

\section{Notes}

The authors declare no competing financial interest.

\section{REFERENCES}

(1) Angell, C. A. Spectroscopy simulation and scattering, and the medium range order problem in glass. J. Non-Cryst. Solids 1985, 73, $1-17$.

(2) Correia, N. T.; Alvarez, C.; Ramos, J. J. M.; Descamps, M. Molecular motions in molecular glasses as studied by thermally stimulated depolarisation currents (TSDC). Chem. Phys. 2000, 252, $151-163$.

(3) Alegría, A.; Goitiandia, L.; Colmenero, J. Interpretation of the TSDC fractional polarization experiments on the $\alpha$-relaxation of polymers. J. Polym. Sci., Part B: Polym. Phys. 2000, 38, 2105-2113.

(4) Kohlrausch, R. Theorie des elektrischen rückstandes in der leidenerflasche. Ann. Phys. 1854, 167, 179-214.

(5) Williams, G.; Watts, D. C. Non-symmetrical dielectric relaxation behaviour arising from a simple empirical decay function. Trans. Faraday Soc. 1970, 66, 80-85.

(6) Delbreilh, L.; Negahban, M.; Benzohra, M.; Lacabanne, C.; Saiter, J. M. Glass transition investigated by a combined protocol using thermostimulated depolarization currents and differential scanning calorimetry. J. Therm. Anal. Calorim. 2009, 96, 865-871.

(7) Correia, N. T.; Ramos, J. J. M.; Descamps, M.; Collins, G. Molecular Mobility and Fragility in indomethacin: a thermally stimulated depolarization current study. Pharm. Res. 2001, 18, 1767-1774.

(8) Viciosa, M. T.; Ramos, J. J. M.; Diogo, H. P. Molecular dynamics of an epoxy resin studied by thermally stimulated depolarization currents. J. Non-Cryst. Solids 2010, 356, 2858-2864.

(9) Brand, R.; Lunkenheimer, P.; Loidl, A. Relaxation dynamics in plastic crystals. J. Chem. Phys. 2002, 116, 10386.
(10) Böhmer, R.; Ngai, K. L.; Angell, C. A.; Plazek, D. J. Nonexponential relaxations in strong and fragile glass formers. $J$. Chem. Phys. 1993, 99, 4201.

(11) Saiter, J. M.; Dargent, E.; Kattan, M.; Cabot, C.; Grenet, J. Fragility index of drawn or annealed poly(ethylene terephthalate) films studied by thermally stimulated depolarisation currents. Polymer 2003, 44, 3995-4001.

(12) Dargent, E.; Bureau, E.; Delbreilh, L.; Zumailan, A.; Saiter, J. M. Effect of macromolecular orientation on the structural relaxation mechanisms of poly(ethylene terephthalate). Polymer 2005, 46, 3090-3095.

(13) Correia, N. T.; Diogo, H. P.; Ramos, J. J. M. Slow molecular mobility in the amorphous solid state of fructose: fragility and aging. J. Food Sci. 2009, 74, E526-E533.

(14) Ramos, J. J. M.; Correia, N. T.; Diogo, H. P. TSDC as a tool to study slow molecular mobility in condensed complex systems. J. NonCryst. Solids 2006, 352, 4753-4757.

(15) Hutchinson, J. M. Interpretation of glass transition phenomena in the light of the strength-fragility concept. Polym. Int. 1998, 47, $56-64$.

(16) Wang, L.-M.; Angell, C. A.; Richert, R. Fragility and thermodynamics in nonpolymeric glass-forming liquids. J. Chem. Phys. 2006, 125, 074505.

(17) Arnoult, M.; Dargent, E.; Mano, J. F. Mobile amorphous phase fragility in semi-crystalline polymers: Comparison of PET and PLLA. Polymer 2007, 48, 1012-1019.

(18) Kunal, K.; Robertson, C. G.; Pawlus, S.; Hahn, S. F.; Sokolov, A. P. Role of chemical structure in fragility of polymers: a qualitative picture. Macromolecules 2008, 41, 7232-7238.

(19) Dudowicz, J.; Freed, K. F.; Douglas, J. F. Fragility of GlassForming Polymer Liquids. J. Phys. Chem. B 2005, 109, 21350-21356.

(20) Qin, Q.; McKenna, G. B. Correlation between dynamic fragility and glass transition temperature for different classes of glass forming liquids. J. Non-Cryst. Solids 2006, 352, 2977-2985.

(21) Doolittle, A. K. The Technology of Solvents and Plasticizers; John Wiley and Sons, Inc.: New York, USA, 1954.

(22) Doolittle, A. K. Mechanism of Plasticization. In Plasticizer Technology; Bruins, P. F., Ed.; Reinhold: New York, USA, 1982; Chapter 1.

(23) Sears, J. K.; Darby, J. R. Mechanism of Plasticizer action. In The Technology of Plasticizers; Sears, J. K., Darby, J. R., Eds.; John Wiley and Sons, Inc.: New York, USA, 1982; Chapter 2, pp 35-77.

(24) Marcilla, A.; Beltran, M. Mechanisms of Plasticizers Action. In Handbook of Plasticizers; Wypych, G., Ed.; ChemTech Publishing: Toronto, Scarborough, 2004; Chapter 5, pp 107-121.

(25) Dobircau, L.; Delpouve, N.; Herbinet, R.; Domenek, S.; Le Pluart, L.; Delbreilh, L.; Ducruet, V.; Dargent, E. Molecular mobility and physical ageing of plasticized poly(lactide). Polym. Eng. Sci. 2014, $55,858-865$.

(26) Monnier, X.; Delpouve, N.; Basson, N.; Guinault, A.; Domenek, S.; Saiter, A.; Mallon, P. E.; Dargent, E. Molecular dynamics in electrospun amorphous plasticized polylactide fibers. Polymer 2015, $73,68-78$.

(27) Delpouve, N.; Araujo, S.; Domenek, S.; Guinault, A.; Delbreilh, L.; Dargent, E. Relaxation Dynamics in Plasticized Polylactide. AIP Conference Proceedings, 2018; Vol. 1981, p 020055.

(28) Vogel, H. The temperature dependence law of the viscosity of fluids. Phys. Z. 1921, 22, 645-646.

(29) Fulcher, G. S. Analysis of recent measurements of the viscosity of glasses. J. Am. Ceram. Soc. 1925, 8, 339-355.

(30) Tammann, G.; Hesse, W. Die Abhängigkeit der Viskosität von der Temperatur bei unterkühlten Flüssigkeiten. Z. Anorg. Allg. Chem. 2004, 156, 245-257.

(31) Alegría, A.; Goitiandía, L.; Tellería, I.; Colmenero, J. $\alpha$ Relaxation in the Glass-Transition Range of Amorphous Polymers. 2. Influence of Physical Aging on the Dielectric Relaxation. Macromolecules 1997, 30, 3881-3887. 
(32) Adam, G.; Gibbs, J. H. On the temperature dependence of cooperative relaxation properties in glass-forming liquids. J. Chem. Phys. 1965, 43, 139-146.

(33) Dyre, J. C. The glass transition and elastic models of glassforming liquids. Rev. Mod. Phys. 2006, 78, 953.

(34) Ediger, M. D.; Angell, C. A.; Nagel, S. R. Supercooled Liquids and Glasses. J. Chem. Phys. 1996, 100, 13200.

(35) Hecksher, T.; Nielsen, A. I.; Olsen, N. B.; Dyre, J. C. Little evidence for dynamic divergences in ultraviscous molecular liquids. Nat. Phys. 2008, 4, 737-741.

(36) Martinez-Garcia, J. C.; Rzoska, S. J.; Drozd-Rzoska, A.; Martinez-Garcia, J. A universal description of ultraslow glass dynamics. Nat. Commun. 2013, 4, 1823.

(37) Donth, E. The size of cooperatively rearranging regions at the glass transition. J. Non-Cryst. Solids 1982, 53, 325-330.

(38) Davies, M.; Hains, P. J.; Williams, G. Molecular motion in the supercooled liquid state: ion pairs in slow motion. J. Chem. Soc., Faraday Trans. 2 1973, 69, 1785-1792.

(39) Sokolov, A. P.; Rössler, E.; Kisliuk, A.; Quitmann, D. Dynamics of strong and fragile glass formers: Differences and correlation with low-temperature properties. Phys. Rev. Lett. 1993, 71, 2062.

(40) Hong, L.; Novikov, V. N.; Sokolov, A. P. Is there a connection between fragility of glass forming systems and dynamic heterogeneity/ cooperativity? J. Non-Cryst. Solids 2011, 357, 351-356.

(41) Araujo, S.; Batteux, F.; Li, W.; Butterfield, L.; Delpouve, N.; Esposito, A.; Tan, L.; Saiter, J.-M.; Negahban, M. A structural interpretation of the two components governing the kinetic fragility from the example of interpenetrated polymer networks. J. Polym. Sci., Part B: Polym. Phys. 2018, 56, 1393-1403.

(42) Nakanishi, M.; Nozaki, R. Model of the cooperative rearranging region for polyhydric alcohols. Phys. Rev. E: Stat., Nonlinear, Soft Matter Phys. 2011, 84, 011503.

(43) Dhotel, A.; Chen, Z.; Sun, J.; Youssef, B.; Saiter, J.-M.; Schönhals, A.; Tan, L.; Delbreilh, L. From monomers to selfassembled monolayers: the evolution of molecular mobility with structural confinements. Soft Matter 2015, 11, 719-731.

(44) Grigoras, C. V.; Grigoras, A. G. Nanoscale cooperativity on a series of statistical methacrylates copolymers with electron donoracceptor pendant groups. J. Therm. Anal. Calorim. 2010, 103, 661668.

(45) Arabeche, K.; Delbreilh, L.; Adhikari, R.; Michler, G. H.; Hiltner, A.; Baer, E.; Saiter, J.-M. Study of the cooperativity at the glass transition temperature in PC/PMMA multilayered films: influence of thickness reduction from macro- to nanoscale. Polymer 2012, 53, 1355-1361.

(46) Moynihan, C. T.; Easteal, A. J.; Wilder, J.; Tucker, J. Dependence of the glass transition temperature on heating and cooling rate. J. Phys. Chem. 1974, 78, 2673-2677.

(47) Hodge, I. M. Enthalpy relaxation and recovery in amorphous materials. J. Non-Cryst. Solids 1994, 169, 211-266.

(48) Hutchinson, J. M. Physical aging of polymers. Prog. Polym. Sci. 1995, 20, 703-760.

(49) Godard, M.-E.; Saiter, J.-M.; Cortés, P.; Montserrat, S.; Hutchinson, J. M.; Burel, F.; Bunel, C. Enthalpy relaxation in polymethyl $(\alpha$-n-alkyl)acrylates: effect of length of alkyl chain. $J$. Polym. Sci., Part B: Polym. Phys. 1998, 36, 583-593.

(50) Lacey, A. A.; Price, D. M.; Reading, M. Theory and Practice of Modulated Temperature Differential Scanning Calorimetry. In Modulated Temperature Differential Scanning Calorimetry; Reading, M., Hourston, D. J., Eds.; Springer: Dordrecht, Netherlands, 2006; Vol. 6, Chapter 1, pp 1-81.

(51) Weyer, S.; Hensel, A.; Schick, C. Phase angle correction for TMDSC in the glass-transition region. Thermochim. Acta 1997, 304305, 267-275.

(52) Havriliak, S.; Negami, S. A complex plane analysis of $\alpha$ dispersions in some polymer systems. J. Polym. Sci., Polym. Symp. 1966, 14, 99-117.

(53) Arrese-Igor, S.; Alegría, A.; Colmenero, J. Chain dynamics on crossing the glass transition: nonequilibrium effects and recovery of the temperature dependence of the structural relaxation. ACS Macro Lett. 2014, 3, 1215-1219. 